\title{
Antiseptic Treatment of Povidone-Iodine Solution as a Countermeasure against Staphylococcus Aureus in Atopic Dermatitis
}

\author{
Sugimoto $\mathrm{K}^{1^{*}}$, Hattori $\mathrm{T}^{2}$, Kitukawa $\mathrm{Y}^{3}$, Aotsuka $\mathrm{A}^{3}$, Wada $\mathrm{T}^{3}$, Kubosawa $\mathrm{H}^{4}$ and Ito $\mathrm{S}^{5}$ \\ ${ }^{1}$ Departments of Clinical Allergology, Neurology Clinic \\ Tsudanuma, Funabashi, Japan.
}

${ }^{2}$ Departments of Neurology, Neurology Clinic Tsudanuma, Funabashi, Japan.

${ }^{3}$ Departments of Internal Medicine, Chiba Aoba Municipal Hospital, Chiba, Japan.

${ }^{4}$ Clinical Pathology, Chiba Aoba Municipal Hospital, Chiba, Japan.

Correspondence:

Sugimoto K, Departments of Clinical Allergology, Neurology Clinic Tsudanuma, Funabashi, Japan, E-mail: ka.sugimoto.chiba.jp@nifty. com.

Received: 12 April 2019; Accepted: 09 May 2019

${ }^{5}$ Department of Neurology, Chiba University Graduate School of

Medicine, Chiba, Japan.

Citation: Sugimoto K, Hattori T, Kitukawa Y, et al. Antiseptic Treatment of Povidone-Iodine Solution as a Countermeasure against Staphylococcus Aureus in Atopic Dermatitis. Dermatol Res. 2019; 1(1); 1-3.

ABSTRACT
Many patients with atopic dermatitis have not only skin but also multiple organ disorders such as intestinal tract and
cervical spine. As the cause, the involvement of a toxin (called superantigen) produced by Staphylococcus aureus,
which is detected from the skin of atopic dermatitis, is presumed. As a measure against Staphylococcus aureus, the
use of Povidone-iodine was listed as adjuvant therapy in the Japanese Guidelines for the Management of Atopic
Dermatitis 2018. In the future, we would like to treat atopic dermatitis as a superantigen disease and propose that
Povidone-iodine solution be used in combination with general treatment as a measure against Staphylococcus
aureus.

\section{Keywords}

Atopic dermatitis, Staphylococcus aureus, Superantigen, Disinfectant, Povidone-iodine.

\section{Introduction}

Patients with atopic dermatitis have a lower ability to protect against bacterial infections than healthy people [1-3]. Among them, Staphylococcus aureus easily adheres to the rash area, and Staphylococcus aureus is detected in most cases of patients with moderate to severe atopic dermatitis. By the way, the American Academy of Dermatology in 2014 announced that it would recommend bleach bath therapy as a treatment option for cases with possible involvement of infection in moderate to severe atopic dermatitis [4].

Also, according to the Japanese Guidelines for the Management of Atopic Dermatitis 2018, Povidone-iodine should not be easily used for atopic dermatitis but the use of Povidone-iodine should be considered for cases where infection may be involved. It was stated that the use of Povidone-iodine solution may be considered as adjuvant therapy [5].

\section{Discussion}

It is known that Staphylococcus aureus is separated more frequently in the skin of the affected part of atopic dermatitis patients than in the skin of healthy people, and it has been considered as an exacerbating factor since ancient times [6]. In Japan, Povidoneiodine solution is often used as a disinfectant, and in some cases, its usefulness has been reported (Figure 1 and Table 1) [7]. However, there has been no comparative test with a control so far, and its usefulness remains empirical. The use of povidone-iodine solution may have adverse effects such as exacerbation of dermatitis due to irritation on the sore surface, allergic contact dermatitis, anaphylaxis, and effects on thyroid function $[8,9]$.

In addition, the use of Povidone-iodine is also poorly understood 
on the basis of medical recommendations and may be considered as adjuvant therapy for cases considered to be associated with infection.

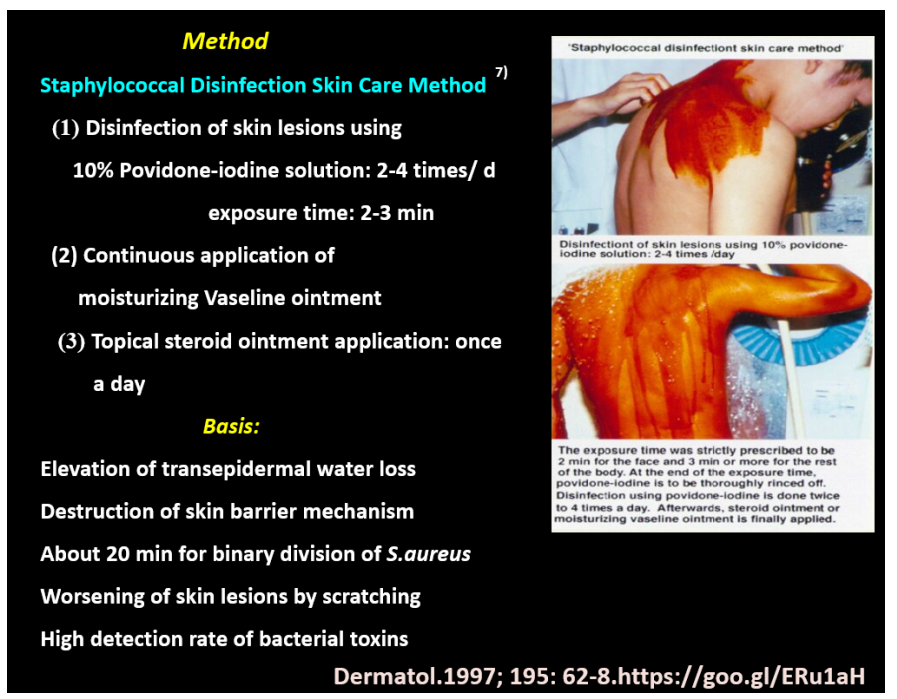

Figure 1: The exposure time was strictly prescribed to be $2 \mathrm{~min}$ for the face and $3 \mathrm{~min}$ or more for the rest of the body. At the end of the exposure time, povidone-iodine is to be thoroughly rinced off. Disinfection using povidone-iodine is done twice to 4 times a day. Afterwards, steroido ointment or moisturizing ointment is finally applied.

1. Povidone-iodine is also a skin irritant, and after application of the skin, the patient should not feel pain due to irritation. In other words, it is necessary to avoid the application of Povidone-iodine solution to the erosion skin and the rash part which exudes skin exudates. If an overall improvement is obtained by the application of Povidone-iodine solution, such a skin surface can also be improved in a short period of time so that the Povidone-iodine solution can be applied.

2. Povidone-iodine solution contains iodine, and it is necessary to minimize the absorption of iodine from the skin. Therefore, it is necessary to protect the time of application to the skin and to wash out Povidone iodine completely.

Moreover, since it has been found that Povidone-iodine solution can kill Staphylococcus aureus in 5 seconds, bacteria on the surface layer can be killed if 5 seconds or more of Povidone-iodine solution has passed. So we recommend that you apply Povidone-iodine solution to the skin and rinse away as soon as the patient feels pain. However, experience shows that if the patient is 5 years of age or older, the face improves in 2 minutes for a face and non-face skin for 3 minutes for an application time, and the rash has been improved in many cases. We think that this leads to the sterilization of deep Staphylococcus aureus by setting the disinfection time to some extent.

3. Since the skin of the face is anatomically thin in the epithelium and susceptible to irritation, the stock solution of Povidone-iodine is too irritating. Therefore, for the disinfection of the skin of the face of atopic dermatitis over 5 years old, it is used by diluting the Povidone-iodine liquid 6 times. For children under 5 years of age, it is recommended to use Povidone-iodine in consideration of dilution depending on the degree.

Table 1: Practical notes of Staphylococcal Disinfection Skin Care Method [7] for atopic dermatitis.

By the way, Staphylococcus aureus detected in patients with atopic dermatitis produces a high rate of toxin. The toxin promotes the secretion of extraordinary cytokines [10]. In addition, we have already reported that in patients with atopic dermatitis, not only skin but also intestinal and cervical spine disorders have been recognized in many cases [11-18]. Moreover, it has also been reported that in 21 cases out of 32 cases, disorders of the intestinal tract and cervical spine were recognized simultaneously in the examination of the same case [15-17]. In addition, it has already been reported that duodenitis and cervical spine amelioration are improved by the treatment using Povidone-iodine solution together with general treatment. By the way, there are also reports that Staphylococcus aureus is involved in the onset and exacerbation in animal experiments [19]. Therefore, we have reported that the cytokine produced by Staphylococcus aureus as a cause of multiple organ failure may be causing the failure [15].

Thus, Staphylococcus aureus control in patients with atopic dermatitis is important, and bleach bath therapy has already been incorporated into the treatment guidelines in the United States. Povidone-iodine can also kill MRSA, and we have already reported that MRSA can be eradicated in all patients with atopic dermatitis in which MRSA [11] is involved. When it is considered that atopic dermatitis is a superantigen disease, Staphylococcus aureus control in atopic dermatitis is important. Although this Povidoneiodine solution contains iodine, it has already been reported that the thyroid disorder is not recognized even in the examination of the injury to the thyroid of iodine absorbed from the skin by the treatment of flushing the Povidone-iodine solution $[7,11]$.

\section{Conclusion}

When it is considered that atopic dermatitis is superantigen disease, measures against Staphylococcus aureus are important. There has been a large number of reports that if a treatment that uses Povidoneiodine solution that can also kill MRSA in combination with general treatment is used, rapidly and remarkable improvement of rashes and laboratory data in patients with atopic dermatitis can be obtained. The Japanese Guidelines for the Management of Atopic Dermatitis 2018 also stated that the use of Povidone-iodine as adjunctive treatment was used with caution for side effects. In the future, it is recommended to use povidone-iodine together with general treatment in cases where general treatment is not effective enough as one of the treatments for atopic dermatitis.

\section{References}

1. Imayama S, Shimozono Y, Hoashi M, et al. Reduced secretion of IgA to skin surface of patients with atopic dermatitis. J Allergy Clin Immunol. 1994; 94: 195-200.

2. Ternowitz T, Herlin T. Defective monocyte and polymorphonuclear leukocyte chemotaxis and clinical characteristics in atopic dermatitis. Arch Dermatol Res. 1986; 278: 454-459.

3. Schöpf E, Kapp A. Chemiluminescence Response of Polymorphonuclear Leukocytes in Atopic Dermatitis. Int Arch Allergy Appl Immunonol. 1987; 82: 380-382.

4. https://www.aad.org/

5. https://www.dermatol.or.jp/uploads/uploads/files/guideline/ atopic_gl1221.pdf

6. Rudikoff D, Lebwohl M. Atopic dermatitis. Lancet. 1998; 351: 1715-1721.

7. Sugimoto K, Kuroki H, Kanazawa M, et al. New successful treatment with disinfectant for atopic dermatitis. Dermatol. 
1997; 195: 62-68.

8. Shigeko IIjima, Miyako Kuramochi. Postoperative contact dermatitis with $10 \%$ povidone iodine solution. The Japanese Journal of Dermatology. 1999; 109: 1029-1041.

9. Pedrosa C, Costa H, Oliveira G, et al. Anaphylaxis to povidone in a child. Pediatr Allergy Immunol. 2005; 16: 361-362.

10. White J, Herman A, Pullen AM, et al. The V beta-specifi superantigen staphylococcal enterotoxin B: stimulation of mature $\mathrm{T}$ cells and clonal detection in neonatal mice. Cell. 1989; 56: 17-35.

11. Sugimoto K, Ishikawa N, Sugioka T. Isojin ${ }^{\circledR}$ disinfectant therapy for atopic dermatitis. Japanese J Pediatric Dermatol. 1998; 17: 103-107.

12. Sugimoto K, Ishikawa N, Sugioka T, et al. The importance of disinfection therapy using povidone-iodine solution in atopic dermatitis. Dermatology. 2002; 204: 63-69.

13. Sugimoto K, Ishikawa N, Terano T, et al. The importance of Bacterial Superantigens Produced by Staphylococcus aureus in the Treatment of Atopic Dermatitis Using Povidone-Iodine.
Dermatology. 2006; 212: 26-34

14. Ito S, Hattori T, Fukutake T, et al. Is atopic dermatitis a risk factor for intervertebral disc degeneration? A preliminary clinical and MRI study. J Neurol Sci. 2003; 206: 39-42.

15. Sugimoto K, Kitukawa Y, Aotsuka A, et al. Is Atopic Dermatitis One of the Superantigens Diseases? J Dermatolog Clin Res. 2015; 3: 1052-1053.

16. Sugimoto K. Staphylococcus aureus vs. Atopic Dermatitis. J Pharm Microbiol. 2016; 2: 1-3.

17. Sugimoto K, Hattori T, Kitukawa $\mathrm{Y}$, et al. Importance of Measures against Staphylococcus aureus in Atopic Dermatitis as a Superantigen Disease. Sci J Clin Res Dermatol. 2017; 2: 007-009.

18. Sugimoto K, Hattori T, Kitukawa Y, et al. Significance of Disinfectants for the Treatment of Atopic Dermatitis, J Allergy Ther. 2018; 9: 1-3

19. Kobayashi T, Glatz M, Horiuchi K, et al. Dysbiosis and Staphylococcus aureus Colonization Drives Inflammation in Atopic Dermatitis. J Immunity. 2015; 42: 756-766. 